\title{
TOLLING MOTORWAYS IN THE TIME OF ECONOMIC DOWNTURN: THE CASE OF PORTUGAL
}

\author{
Marco AMORIM, António LOBO*, António COUTO \\ Research Centre for Territory, Transports and Environment; Faculty of Engineering, University of Porto, Portugal
}

Received 27 March 2017; revised 21 July 2017; accepted 24 November 2017

\begin{abstract}
The recent European debt crisis has led many governments to impose strict measures to alleviate public expenditure and increase revenue, especially in the southern countries. Many public services and infrastructures became more costly for users due to the increase of existing fees or the implementation of new ones. In Portugal, one of the measures adopted by the government consisted in the removal of shadow tolls and the application of the user-pays principle to the entire network of rural motorways. To rapidly implement, this measure, in the context of financial constraints, the Electronic Toll Collection (ETC), materialized by the installation of gantries in selected motorway segments, was the preferred solution over the more time and resource consuming construction of toll plazas. Toll revenue is directly collected by the state, which intends to cover, at least partially, the expenses associated with the contractual payments to private concessionaires for the traffic using these roads. The main objective of this research is to provide a new optimization tool to allocate toll gantries to the segments of an existing motorway with the aim of maximizing toll revenue, based on the case study of Portuguese motorways. A macroscopic decision model that predicts drivers' decision on using a tolled segment or the fastest alternative route and an optimization model that sets the price and location of toll gantries along a given motorway work together to provide a valuable tool to maximize the revenue. A special focus has been placed on scenarios of economic downturn, characterized by a negative growth of the Gross Domestic Product (GDP); however, the new tool allows making explanatory analyses for situations of economic growth. The results show that the optimal configuration for ETC vary with the macroeconomic scenario, with the number of tolled segments and price per kilometre inducing relevant variations on the revenue and traffic volume. The proposed methodology may be applied in other countries to assist decision makers in the implementation of ETC in motorways under different conditions. The required data is easy to collect from sources at the disposal of the practitioners.
\end{abstract}

Keywords: electronic toll collection, motorways, macroeconomic situation, toll location, toll revenue, binary choice model, optimization model.

\section{Introduction}

In the early 2000's, the Portuguese Government took the decision of expanding significantly the country's primary road network through the construction of eight new rural motorways. These motorways, commonly known as SCUTs (Sem Custo para os UTilizadores), from the Portuguese acronym for free-of-charge for road users, were initially conceived as non-tolled roads. However, to avoid a large initial investment by the state, the SCUTs were subject to shadow tolls under arrangements of Public-Private Partnerships (PPPs). These PPPs are long-term contracts between the state and private companies, establishing that the concessionaires are responsible for the construction and operation of the motorways, usually for a period of
30 years, while the state is obligated to pay for the traffic using each road during the same period.

With the outbreak of the Portuguese financial crisis in 2010 and the subsequent bailout programme signed between the Portuguese Government, the European Commission, the European Central Bank, and the International Monetary Fund, the Portuguese Government was urged to renegotiate several PPP contracts in force. Consequently, drivers started to pay tolls at the eight motorway concessions, which from then on, became known as former SCUTs. The toll revenue from these roads is directly collected by the state and destined to cover, at least partially, the contractual payments to the concessionaires.

${ }^{\star}$ Corresponding author. E-mail: lobo@fe.up.pt 
Compared to conventional tolled motorways, in which the introduction of tolls was planned at the design stage, the former SCUTs generically present higher densities of interchanges to favour short-distance trips and improve the accessibility to smaller villages. In this sense, the solution adopted in Portugal for conventional motorways, consisting in the construction of toll plazas to control every motorway entrance and exit, was considered excessively expensive and of slow execution in the case of the former SCUTs. Therefore, the Portuguese Government opted for collecting tolls exclusively by means of electronic devices.

Electronic Toll Collection (ETC) is an emerging technology to implement road pricing policies. The devices used to charge vehicles, either by license plate recognition or in-vehicle transponders, are relatively easy to install, avoiding major construction works and reducing the staff needed to operate the system. ETC has become popular among road authorities and concessionaires, especially for motorway tolling and congestion charging applications (Hau 2005). In urban environment, congestion charging has been materialized by ETC in some large cities to curb congestion, mitigate the environmental and safety impacts of road traffic, and finance public transport (Santos 2005; Eliasson et al. 2009; Odeck, Bråthen 1997; Rotaris et al. 2010). In smaller cities, ETC has been used to reduce the number of vehicles in historical centres and promote a friendlier environment for pedestrians and tourists (Ieromonachou et al. 2004; Attard, Ison 2010). In the case of motorways, ETC was initially introduced in some lanes of toll plazas along with manual lanes. The much smaller traffic delays observed in ETC lanes (Al-Deek et al. 1996; Zarrillo et al. 1997; Levinson, Chang 2003) soon attracted more users to the system. Portugal was the first country to offer a universal service of automatic payment at all its toll plazas, when introduced the Via Verde system back in 1995. The system consists of ETC devices installed at exclusive lanes that connect to a specific in-vehicle transponder to automatically debit the toll fee in the user's bank account.

The solution adopted to implement tolls at the former SCUTs, although benefiting from the accumulated experience in ETC, differs from the solution adopted at conventional motorways in two major points. First, in the former SCUTs, ETC is materialized by the installation of toll gantries in certain segments of the motorway, i.e., between selected pairs of consecutive interchanges (Figure 1), contrasting with the conventional solution of constructing toll plazas with both automatic and manual lanes at every entrance and exit. This choice leaves certain segments of the former SCUTs untolled, which does not happen in conventional motorways. Second, all the vehicles using the former SCUTs are identified at the ETC gantries; in the case of conventional motorways, only the vehicles using automatic payment lanes at toll plazas are identified. The gantries at the former SCUTs are interoperable with the existing Via Verde system, but the installation of an in-vehicle transponder for automatic payment

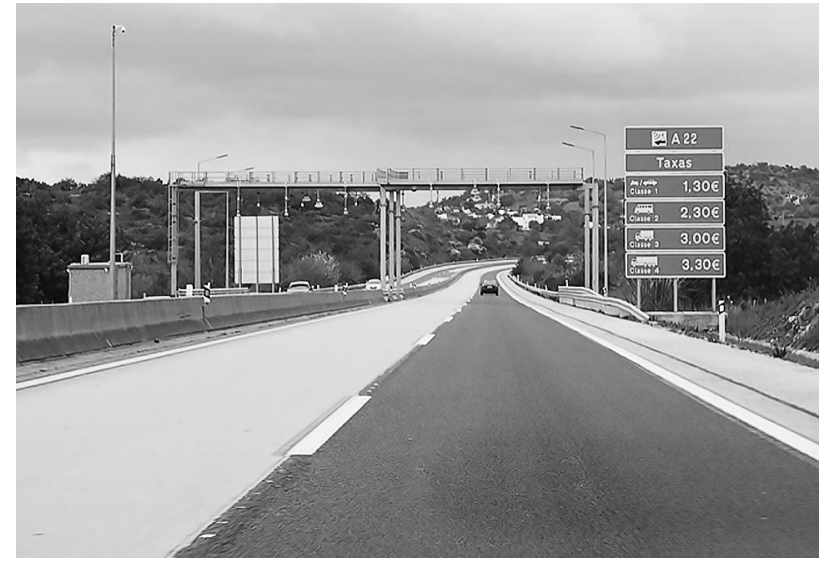

Figure 1. Example of ETC in a former SCUT in Portugal

is still optional, because drivers can choose to pay within a legal period of five working days after the trip.

The decision about the gantries' location, i.e., the segments to be tolled, may be subject to diverse technical criteria, such as the maximization of the revenue, the minimization of the impacts on the local economy and mobility, and the characteristics of the alternative routes. The public acceptance of road pricing is also a relevant issue to be considered by decision-makers (Jakobsson et al. 2000; Chen et al. 2007). The application of such criteria determine if a segment should or not be tolled.

Given the context of economic downturn and financial assistance that led to the end of non-tolled rural motorways in Portugal, this research is focused on maximizing the revenue of the implementation of ETC at an existing motorway. To maximize the revenue, a methodical installation of ETC is required (Banister 2007; De Palma et al. 2011), otherwise, traffic losses may seriously compromise the expected results. In this sense, a new tool is developed, combining a drivers' decision model and an optimization model to allocate ETC gantries to the segments of a given motorway for different macroeconomic scenarios. The tool is applied to the case study of a former SCUT in Portugal, giving a particular emphasis to a context of economic downturn. Nevertheless, the model application and the exploratory analysis of results has demonstrated the capabilities of this tool to propose a diversified set of solutions to address the maximization of toll revenue under different perspectives and constraints.

Despite some efforts have been made to optimize the operation of motorway corridors, such as the ones by Danczyk, Liu (2011) and Repolho et al. (2010, 2011) regarding the location of speed sensors and interchanges, respectively, little research has been conducted on the optimization of toll collection sites. The tool presented in this paper contributes to address this issue, particularly concerning the application of an emerging technology that is still not generalized among tolled motorways. The implementation of tolls in roads initially conceived as nontolled infrastructures may not be a common procedure; 
however, in times of economic uncertainty, the methodology developed for the case study of Portugal may be reproduced in other countries under diverse economic situations.

The remainder of the paper is structured as follows. First, the methodological approach is presented, containing the description of the drivers' decision model and the optimization model. In the model application, the case study of Portugal's former SCUTs is used to estimate the drivers' decision model, determining the probability of drivers using the tolled motorway or the fastest alternative route. The optimization model to define the location of ETC gantries is then applied to one of the former SCUTs, exploring possible economic scenarios and constraints in diverse exploratory runs. The paper proceeds with the discussion of results, presenting the outcomes from the exploratory runs and highlighting the multiple capabilities of the developed methodology. The final section summarizes the main conclusions of this research.

\section{Methodological approach}

The aim of this study is to analyse and provide solutions for toll gantry location in motorways by maximizing the revenue according to the economic environment. To work on a macro level and produce an easy-to-use tool to assist the definition of toll location and pricing, a two-step procedure is proposed:

- a simplified drivers' choice model to avoid the complexity of using an origin-destination (O-D) matrix;

- an optimization model to maximize toll revenue.

To analyse the impact of the economic environment on the drivers' decision of using a tolled segment or an alternative road, the growth of the Gross Domestic Product (GDP) was chosen to represent the users' purchasing power, while the fuel price variation reflects road transportation costs. The first step is to study how the motorway users react to ETC implementation at a certain segment: if they use the tolled segment or an alternative road, freeof-charge, but facing a greater travel time and distance. To achieve this goal, a logistic regression was modelled using the eight Portuguese former SCUTs, which started to be tolled during the recession period, when regional GDP plummeted in as much as $4 \%$. Second, an optimization model was developed to determine the location of toll gantries and corresponding prices by maximizing the toll revenue and considering the drivers' choice resulting from the first model. The combined model was then applied to one of the former SCUTs. Several runs were made to provide solutions leading to the maximum revenue for different GDP growths rates, and particularly to assess the feasibility of ETC on alleviating public expenditure during recession periods.

\subsection{Binary choice model}

The relevance of a binary choice model in this context stands for the prediction of the number of vehicles at a given motorway segment depending on the presence of tolls, the toll price, the country's macroeconomic situation, and externalities. The discrete model with a binary option measures the probability of aggregated drivers using each motorway tolled segment, or a longer, slower, but free-of-charge alternative.

The first problem consists in understanding the drivers' preference, often made before the trip or in its initial moments. Drivers' choice on using a tolled segment or a free-of-charge alternative can be assessed, and consequently modelled, through the use of $\mathrm{O}-\mathrm{D}$ matrices before and after the introduction of tolls. However, when this data is not available, the use of existing traffic counts, in the present case observed at each motorway segment before and after toll implementation, allows for a simplified, segment-by-segment approach. In this approach, drivers' preference is aggregated in a binary choice at the moment before they enter in each one of the motorway segments; either they use the motorway segment that is tolled at a certain price (option A), or they use the fastest alternative road that is free-of-charge, but implies a longer and slower trip (option B).

The decision model returns the probability of drivers using option A or B depending on the toll price and differences on travel time and distance. Thus, it is possible to predict the percentage of runaway traffic from the tolled section. A variable reflecting the presence of two consecutive tolled segments is used to more accurately represent a premeditated option.

The dichotomous nature of the dependent variable, set to 1 if the aggregated drivers' decision is option $\mathrm{A}$ and to 0 if option B, suggests the use of a binary logistic regression to model the probabilistic aggregated decision. The probability of using option A instead of B, segment by segment, is estimated through the maximum likelihood method. The systematic part of the utility is formulated by Equation (1):

$$
f\left(x_{m}\right)=\beta_{0}+\sum_{l=1}^{n} \beta_{l} \cdot x_{m},
$$

where: $x_{m}$ - explanatory variables; $\beta$ - regression coefficients; $m \in\{1, \ldots, n\}$. The conditional probability of a positive outcome (option A, $Y=1$ ) is determined by Equation (2):

$$
\operatorname{Prob}\left(Y=1 \mid x_{m}\right)=\frac{f\left(x_{m}\right)}{1+f\left(x_{m}\right)} .
$$

The resulting model is used to calculate the probability of a user choosing a tolled segment, i.e., option A, given the characteristics of options A and B and considered externalities (explanatory variables $c$ ).

\subsection{Optimization model}

The optimization model allows defining the best configuration for ETC to maximize the revenue according to the binary choice model and the characteristics of options $\mathrm{A}$ and $\mathrm{B}$. The best solution may be neither introducing tolls 
in every motorway segment nor adopting higher prices, because such measures may cause a severe decrease in the traffic using the motorway. Thus, the objective of applying an optimization model together with a binary choice model to describe the aggregated drivers' choice is to assess the optimal location of toll gantries and the corresponding appropriate prices to maximize toll revenue according to the prevailing economic context.

The first step to build the optimization model is to estimate the traffic loss at a motorway segment where a toll gantry can be installed, using the previously presented binary choice model. With this model, the probability of using the tolled segment for each price is estimated, which translates into a percentage of traffic loss on the motorway. Different toll prices per kilometre were established to comply with possible situations; this is the same as having an integer variable limited between two values, but allows the use of a binary variable for a better management of the true or false situations inherent to the model. For modelling purposes, it is a priori established that each motorway segment is composed by two sections, each one corresponding to a traveling direction. This assumption arises from potentially different traffic flows and characteristics of the alternative roads from one direction to the other.

The decision variable toll $_{i j}$ is set to 1 if toll price category $j$ is applied in section $i$ and to 0 otherwise. Then, it is possible to define a model to optimize gantry locations by maximizing the revenue, considering that the presence of tolls decreases traffic in a nonlinear variation with the convenience of option B and toll concentration. Equation (3) represents the objective function:

$$
\begin{aligned}
& \max \sum_{i=1}^{N S} \sum_{j=1}^{N C}\left(\operatorname{toll}_{i j} \cdot c_{j} \cdot p t_{i j} \cdot t_{i} \cdot l_{i}\right)- \\
& \sum_{i=1}^{N S} \sum_{j=1}^{N C}\left(\operatorname{toll}_{i j} \cdot c_{j} \cdot p t_{i j} \cdot t_{i} \cdot l_{i} \cdot p r_{i j} \cdot \sum_{j=1}^{N C} \text { toll }_{i+1, j}\right),
\end{aligned}
$$

where: $i$ - motorway section; NS - number of sections; $j$ - price category; $N C$ - number of price categories; $l_{i}$ length of motorway section $i ; c_{j}$ - toll price per kilometre for category $j ; p t_{i j}$ - proportion of vehicles using section $i$ if toll price category $j$ is applied; $t_{i}$ - number of vehicles in section $i$ if no toll is implemented; $p r_{i j}$ - proportion of vehicles lost if toll price per kilometre $j$ is applied in section $i$ and any toll price is applied in section $i+1$. The parameter $\sum_{j=1}^{N C}$ toll $_{i+1, j}$ captures the existence of tolls in the following section, assuming the value 1 if any toll is charged and 0 otherwise.

In the latter case, the second term in Equation (3) becomes null and no penalty is applied to the objective function. To cope with a realistic situation, the optimization model includes the constraints represented by Equations (4)-(7):

$$
\sum_{j=1}^{N C} \operatorname{toll}_{i j} \leq 1, \forall i
$$

$$
\begin{aligned}
& \sum_{j=1}^{N C} \operatorname{toll}_{i j}=\sum_{j=1}^{N C} \operatorname{toll}_{N S-i, j}, \quad \forall i ; \\
& \sum_{i=1}^{N S} \sum_{j=1}^{N C} \operatorname{toll}_{i j}=N G \cdot 2 ; \\
& \sum_{i=1}^{N S} \operatorname{toll}_{i j}=0, \quad \forall j \neq i,
\end{aligned}
$$

where: $N G$ - number of toll gantries.

The constraint in Equation (4) imposes that only one toll is implemented in each section. It would make no sense to allow multiple gantries in the same section as it would be the same as having a higher toll price per kilometre in just one gantry.

Different prices per kilometre in the same segment are allowed by considering both directions separately. In this application, if a section is tolled, the corresponding section in the opposite direction must be tolled as well. Therefore, the constraint set by Equation (5) ensures that if a toll exists between two interchanges, it exists in both directions, and only price may vary within each other. The parameter $\sum_{j=1}^{N C} t_{o l l} l_{N S-i, j}$ represents the existence or not of tolls in the segment containing section $i$.

To analyse the revenue and traffic variation with the number of tolls for a given GDP growth, an optional constraint to set the total number of gantries is implemented by Equation (6). The constraint in Equation (7) can be used to fix a single price per kilometre for all the tolled segments. By testing different prices, it is possible to identify the best solution for different macroeconomic situations.

\section{Application of the model}

The binary choice model was applied to all the eight former SCUTs in Portugal to determine the probability equation that returns the percentage of traffic in option A, depending on the toll price and the characteristics of option B. Together with the optimization model, it was possible to assess the influence of the GDP growth; this parameter reflects the general macroeconomic situation of a country, being a valuable indicator of a recession period. To comply with the objectives of the study, the regional GDP growth was included in the model as an explanatory variable to represent the macroeconomic situation and its influence on drivers' choice.

The travel times between nodes corresponding to options A and B were obtained from Google Maps (Google LLC 2017). The Average Daily Traffic (ADT) observed in each motorway segment was provided by motorway concessionaires and the Portuguese Institute for the Mobility and Transports (IMT 2017), corresponding to three distinct periods: (1) three years before the introduction of tolls, (2) the first year after the introduction of tolls, considered as an adaptation period, and (3) one year after the 
adaptation period. Separate ADT data for each traveling direction was not available, hence a 50\% split was considered for modelling purposes.

Prior to model estimations, the collected data were treated to normalize the observations through different years after the introduction of tolls. This correction to the data allows considering the effect of GDP growth and fuel price on traffic volume beyond the effect of tolls. Thus, based on data before the implementation of tolls, the function in Equation (8) was used to estimate the traffic volume in the period after the implementation if this had not been done:

$$
t_{i k}=t_{i, k-1} \cdot\left(1.0455+0.0312 \cdot G D P G_{k}-0.0052 \cdot F G_{k}\right),
$$

where: $t_{i k}$ - estimated traffic volume in section $i$ and year $k$; $G D P G_{k}$ - percent GDP growth in year $k ; F G_{k}$ - percent fuel price growth in year $k$.

Equation (8) was modelled using data from the years before the introduction of ETC through a multivariate linear regression. Different variable combinations and transformations were tested, but the non-transformed GDP and fuel price growths were found the simplest and most accurate estimators. An adjusted $R$-squared of 0.36 was obtained and all the parameters revealed to be statistically significant at $1 \%$ level. Subsequently, it was possible to calculate the traffic captured by option B after toll implementation by comparing the observed and estimated traffic in option A.

The binary choice model was estimated using the econometric software LIMDEP 10 . The explanatory variables selected to represent the decision making are the toll price at the road segment (TLLCOST), the difference of travel time between options A and B (TIMEV), the difference of distance between options A and B (DISTV), the GDP growth (GDPG), an interaction term calculated by the product of the GDP growth and the toll price (GDPCOST), a dummy variable accounting for the effects of two consecutive tolled segments, set to 1 if the following segment is also a tolled segment and to 0 otherwise (TOLLNX), a dummy variable representing the adaptation period, set to 1 if the period under analysis is within a period of one year after toll implementation and to 0 otherwise (ADAPT), a dummy variable for the presence of short-distance traffic, set to 1 if the motorway passes near an urban area and to 0 otherwise (URBAN), and a dummy variable for the presence of seasonal/touristic movements, set to 1 if the motorway passes near touristic areas or attractions and to 0 otherwise (SEASON).

The traffic observed along the motorways before and after toll implementation was used to estimate the probabilistic model. To avoid an excessive replication of traffic observations, i.e., an excessive number of observations with the same $x_{m}$ and the same response $Y$, the response of a group of 1000 vehicles was considered as an individual observation. The final database used for model estimation consists of 12555 observations, 9157 of which correspond to the period after toll implementation, and 5488 of these correspond to the adaptation year. All the observations were corrected according to Equation (8). Table 1 presents the results of the logistic regression model.

To implement the optimization model, the case study is focused on just one of former SCUTs. The selected motorway is part of the Portuguese main road network and one of the most used roads for interregional and international journeys. The motorway has a total length of $182.4 \mathrm{~km}$, being composed by 21 segments linking 22 interchanges. During the Portuguese financial crisis, ETC gantries were installed in 13 segments, with the remaining 8 segments being maintained free-of-charge for road users. The general data on the motorway selected for this application are presented in Table 2.

Table 1. Results of logistic regression modelling

\begin{tabular}{|c|c|c|c|}
\hline Variable & Coefficient & Standard error & Mean value \\
\hline Constant & 2.904 & $0.088^{\star}$ & -0.922 \\
\hline GDPG & 0.534 & $0.022^{*}$ & 0.437 \\
\hline ADAPT & 0.631 & $0.055^{\star}$ & 0.267 \\
\hline TOLLNX & -0.897 & $0.050^{*}$ & 9.512 \\
\hline TIMEV & 0.068 & $0.011^{\star}$ & 5.170 \\
\hline DISTV & -0.056 & $0.010^{\star}$ & 0.187 \\
\hline TLLCOST & -2.539 & $0.111^{\star}$ & -0.382 \\
\hline GDPCOST & -0.488 & $0.043^{\star}$ & 0.724 \\
\hline URBAN & -1.667 & $0.070^{*}$ & 0.063 \\
\hline SEASON & -0.438 & $0.098^{*}$ & -0.922 \\
\hline- & $\begin{array}{c}M= \\
\text { model }\end{array}$ & $\begin{array}{c}M C= \\
\text { constants only }\end{array}$ & $\begin{array}{c}M 0= \\
\text { no model }\end{array}$ \\
\hline Log-likelihood & -6169 & -7331 & -8702 \\
\hline $\begin{array}{l}\text { Number of } \\
\text { observations }\end{array}$ & 12555 & & \\
\hline
\end{tabular}

Note: ${ }^{*}$ significant at $1 \%$ level.

The ADT in each motorway segment corresponds to the period between 1 January 2011 and 28 February 2011, i.e., before toll implementation; for modelling purposes, a $50 \%$ traffic split between both directions was considered. The optimization model aims to capture the traffic loss in each motorway segment due to the installation of an ETC gantry. In accordance to the logistic model, drivers assess option B by the delay they are willing to support to save the segment's toll price. Consecutive tolls further increase the probability of drivers choosing option $\mathrm{B}$, because of the increase in the savings/delay ratio. In this application, a segment must be tolled in both directions (paired sections), although prices per kilometre may be different. Figure 1 provides a schematic representation of the case-study motorway segments and corresponding paired sections. To simulate plausible real situations, 11 different prices per kilometre are allowed, varying from 0.07 to 0.17 EUR with steps of 0.01 EUR.

Optimization modelling estimations were made using the software IBM ILOG CPLEX Optimization Studio V12.5. To maximize the objective function (Equation (3)), 
Table 2. General data on the case-study motorway

\begin{tabular}{|c|c|c|c|c|c|}
\hline \multirow{2}{*}{ Segment } & \multicolumn{3}{|c|}{ Option A } & \multicolumn{2}{|c|}{ Option B } \\
\hline & Travel distance $[\mathrm{km}]$ & Travel time [min] & ADT before ETC & Travel distance $[\mathrm{km}]$ & Travel time $[\mathrm{min}]$ \\
\hline $\mathrm{A}$ & 5.6 & 3 & 14673 & 9.1 & 11 \\
\hline $\mathrm{B}$ & 4.2 & 2 & 13886 & 6.6 & 9 \\
\hline $\mathrm{C}$ & 11.0 & 6 & 11328 & 14.2 & 22 \\
\hline $\mathrm{D}$ & 7.2 & 4 & 12305 & 8.4 & 11 \\
\hline$E$ & 6.3 & 3 & 11884 & 10.2 & 18 \\
\hline $\mathrm{F}$ & 5.8 & 3 & 11194 & 7.6 & 11 \\
\hline G & 14.1 & 7 & 11303 & 13.5 & 10 \\
\hline $\mathrm{H}$ & 11.7 & 6 & 8930 & 18.5 & 12 \\
\hline $\mathrm{I}$ & 10.1 & 6 & 6576 & 9.3 & 13 \\
\hline $\mathrm{J}$ & 5.3 & 3 & 14798 & 7.5 & 9 \\
\hline $\mathrm{K}$ & 3.9 & 2 & 14316 & 7.1 & 9 \\
\hline $\mathrm{L}$ & 12.8 & 7 & 8433 & 15.5 & 19 \\
\hline $\mathrm{M}$ & 8.5 & 4 & 7613 & 11.6 & 14 \\
\hline $\mathrm{N}$ & 12.9 & 7 & 7493 & 14.2 & 20 \\
\hline $\mathrm{O}$ & 5.8 & 3 & 8657 & 7.3 & 10 \\
\hline $\mathrm{P}$ & 2.5 & 1 & 9252 & 4.5 & 6 \\
\hline Q & 15.6 & 8 & 10578 & 15.1 & 16 \\
\hline $\mathrm{R}$ & 3.9 & 2 & 7478 & 7.0 & 12 \\
\hline$S$ & 14.5 & 8 & 4964 & 15.6 & 15 \\
\hline $\mathrm{T}$ & 8.1 & 4 & 4669 & 10.4 & 12 \\
\hline $\mathrm{U}$ & 12.6 & 7 & 4034 & 18.6 & 25 \\
\hline Total & 182.4 & 96 & $\mathrm{n} / \mathrm{a}$ & 231.8 & 284 \\
\hline
\end{tabular}

CPLEX solving settings were set as automatic, and Boolean variables were used to set the decision variables as binaries. This leads to a pre-solve process using mixed-integer quadratic programming. Afterwards, the solving process undergoes a mixed-integer programming that emphasizes the balance between optimality and feasibility with a dynamic search method and a deterministic parallel mode with up to 4 threads. Early trial runs of the model were carried out by relaxing the constraint associated with the maximum number of toll gantries (Equation (6)). For running times between 0 seconds and 1 day, the best feasible solutions were reached in less than $300 \mathrm{~s}$. Thus, a running time limit of $300 \mathrm{~s}$ was set for the following experiments.

After the final calibration has been made, several explanatory runs of the optimization model were performed. The first set of exploratory runs provides solutions for the location of toll gantries that maximize the revenue for different GDP growth rates, sitting between -3 and 3\%, with no restrictions on the number of tolled segments and toll prices per kilometre. The second set of exploratory runs is aimed at analysing the effects on toll revenue of limiting the number of tolled segments from 1 to 21 in the case of a negative GDP growth of $-2 \%$, with no restrictions to toll prices per kilometre. Finally, the third set of exploratory runs shows the effects on toll revenue and traffic volume of fixing each one of the considered prices per kilometre at all the tolled segments, for GDP growth rates between -2 and $2 \%$, with no restriction on the number of tolled segments.

\section{Discussion of results}

The first set of exploratory runs allows understanding how the toll location and prices should vary along the motorway for different scenarios of GDP growth. The results are shown in Figure 2. For a negative growth of the GDP, the best solutions to maximize toll revenue are generically associated with lower toll prices per kilometre. In the harshest macroeconomic scenario $(\mathrm{GDPG}=-3 \%)$, three of the motorway segments, I, M, and S, should not even be tolled. Conversely, even in the case of a negative GDP growth, segments $\mathrm{K}, \mathrm{P}$, and $\mathrm{R}$ are tolled at the maximum price per kilometre. These segments are amongst those in which option A represent greater time savings, of approximately $80 \%$, compared to option B. Therefore, despite the fact that, at certain segments, toll prices per kilometre can almost be doubled from an unfavourable to a favourable macroeconomic scenario towards the maximization of toll revenue, the characteristics of the alternative roads play a major role in drivers' choice, regardless the economic situation.

The second set of explanatory runs was focused on the effects of limiting the number of tolled segments under the context of a negative GDP growth. This situation is probably the most similar to the one experienced by the studied motorway at the moment of the introduction of tolls. Figure 3 shows the relation between toll revenue and the number of tolled segments for a GDP growth of $-2 \%$. 


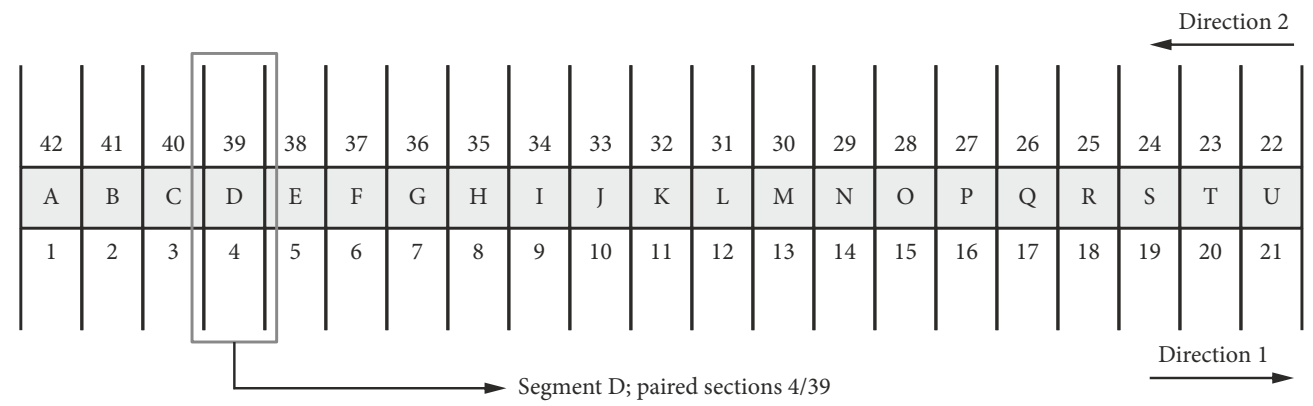

Figure 2. Schematic representation of the motorway segments and sections

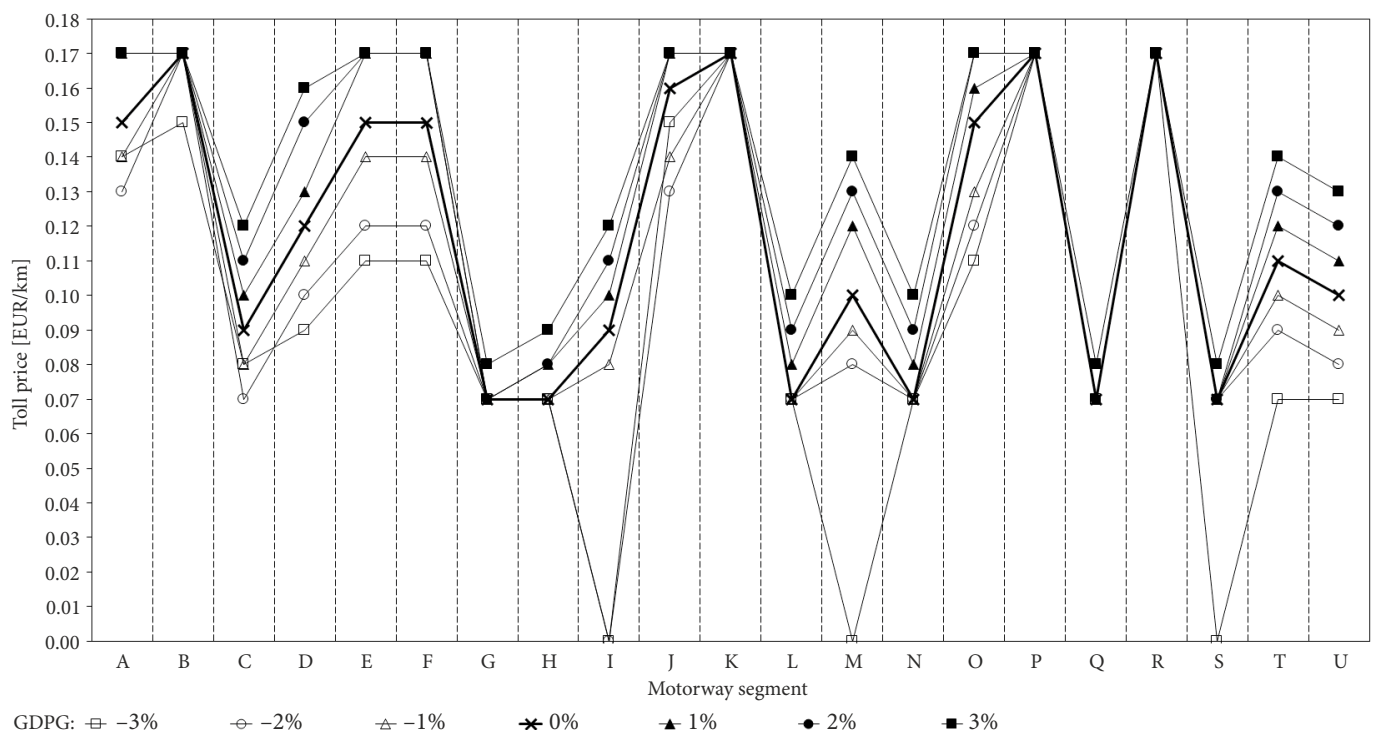

Figure 3. Toll location and prices for different scenarios of GDP growth

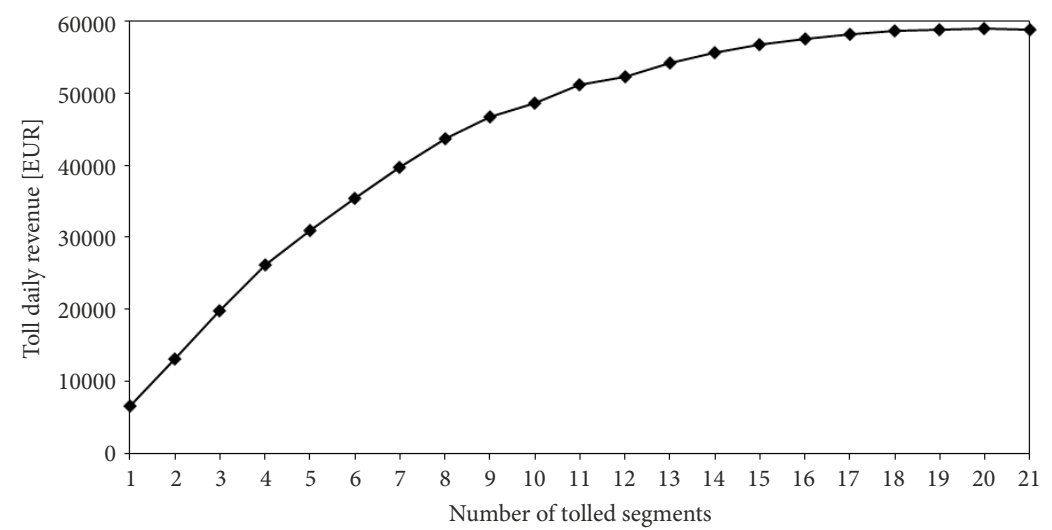

Figure 4. Toll daily revenue according to the number of tolled segments

The marginal effect of increasing the number of tolled segments up to four is approximately constant. From the fifth toll installation onwards, the marginal effect is gradually smaller, being almost null for more than 17 tolled segments, and actually decreasing with the installation of the last possible gantry.

As previously mentioned, the gantries were installed at 13 segments of the case-study motorway during the Portuguese financial crisis. The results in Figure 4 denote that there was little room to increase significantly the revenue by tolling more segments. However, the current solution can be improved by reconfiguring the location of tolled segments and by allowing different prices per kilometre in each direction of the same segment. For example, under the same context of a GDP growth of $-2 \%$, the solution with 13 tolled segments returned by the model represents an estimated increase of around $30 \%$ over the revenue estimated for the current configuration.

Finally, the third set of explanatory model runs allows estimating the maximum revenue for different scenarios of GDP growth if the price policy is to apply a single price per kilometre to all tolled segments. The results are shown 
in Figure 5. The aggravation of the macroeconomic situation decreases the toll price per kilometre leading to the maximum revenue: $0.11 \mathrm{EUR} / \mathrm{km}$ in 20 tolled segments for a GDP growth of $2 \%$ and $0.08 \mathrm{EUR} / \mathrm{km}$ in 19 tolled segments for a GDP growth of $-2 \%$. It is possible to observe that the revenue is much more sensitive to the price per kilometre under a favourable economic environment than under a downturn period. Conversely, in the latter situation, the solutions maximizing the revenue for each price per kilometre present a much greater variation among each other regarding the number of tolled segments.

The impacts of toll implementation on the motorway's traffic volume for the scenarios tested in the third set of explanatory model runs are presented in Figure 6. The aggregated traffic variable represents the sum of all vehicles traversing each one of the motorway segments. Globally, a much smaller number of trips is observed in the scenario of a negative GDP growth, due to a decrease in the economic activity and citizens' income. Moreover, the number of trips performed under a scenario of negative GDP growth seems to be much more affected by the number of tolled segments than by the price per kilometre. In opposition to the revenue, the maximum aggregated traffic is achieved for solutions presenting higher prices per kilometre but much less tolled segments, making easier for drivers to take advantage of the motorway non-tolled segments, while they are more prone to use the alternative roads to overcome tolled segments. In the case of a positive GDP growth, the price per kilometre is preponderant to demand, which does not seem to be affected by the number of tolled segments. Drivers may opt to take the motorway if they accept to pay the toll costs of the segments they want to use. If not, they might just pick up another road or do not make the trip at all, instead of considering to shift between options A and B to avoid tolled segments. Therefore, there might be very different solutions to balance between the impacts on road users and the maximization of toll revenue according to the macroeconomic situation.

\section{Conclusions}

This paper presents an optimization tool to define the motorway segments where tolls should be introduced and the corresponding prices in order to maximize the revenue. The proposed tool includes a binary choice model, accounting for the effects of the economic environment on the drivers' decision between the tolled motorway segments and the corresponding alternative roads. A special focus is placed on the analysis of scenarios of economic downturn, and for that, the case study of optimizing the installation of ETC gantries along a Portuguese motorway that has been tolled since the country's recent financial crisis was selected. The drivers' choice model was generalized for nationwide conditions by using regional data from all the former SCUTs spread across the Portuguese

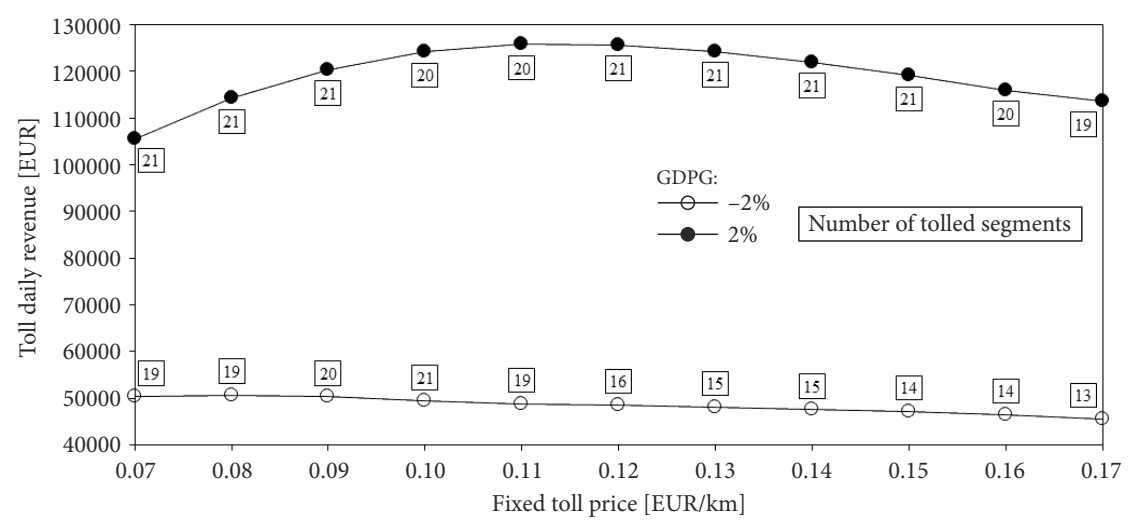

Figure 5. Toll daily revenue for fixed toll prices per kilometre and different GDP growths

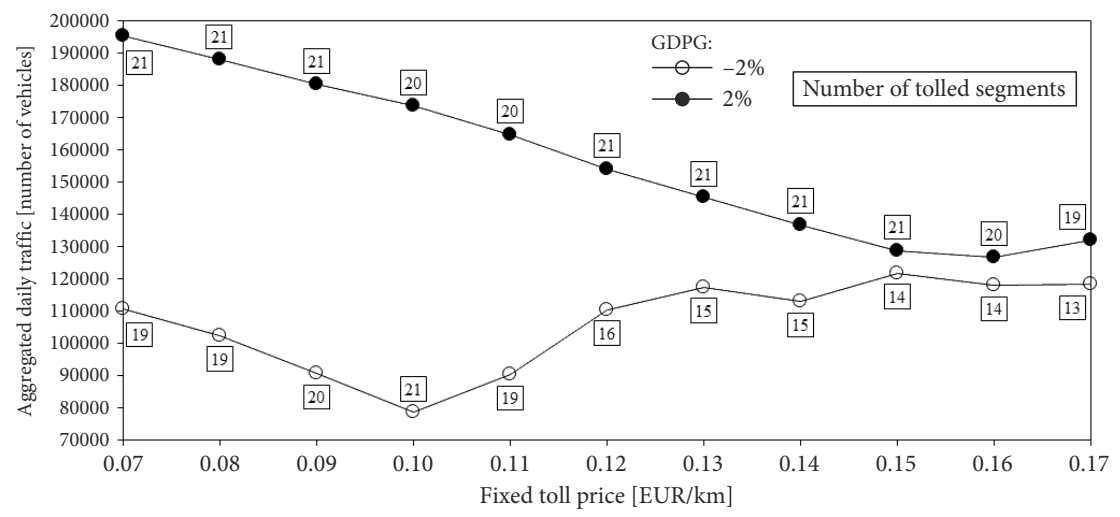

Figure 6. Aggregated daily traffic for fixed toll prices per kilometre and different GDP growths 
territory. The use of the optimization tool may be replicated in other countries, as long as the estimators of the binary choice model are corrected according to the corresponding realities. The required data for this application is usually available to planners and decision makers.

From the optimization modelling results, it was possible to conclude that price discrimination may be a viable policy to increase the revenue and mitigate traffic losses, consisting in an alternative procedure to the installation of additional gantries. In scenarios of negative GDP growth, the decision maker aiming at a maximum revenue may opt for lower prices per kilometre and assess if all the segments should or should not be tolled. In contrast, for positive GDP growths, users are willing to support more tolls and higher prices per kilometre. However, fixing the same price per kilometre is sometimes convenient for regional equity reasons. In this case, the revenue was found to be more dependent on the fixed price per kilometre during favourable economic periods than during unfavourable periods. In the latter situation, because drivers are more prone to detour from the motorway to avoid tolled segments, the configuration of ETC should allow some freeof-charge segments to reduce the overall runaway traffic if the balance between minimizing the impacts on road users and maximizing the toll revenue is at stake.

Another approach used by decision-makers is to establish a priori the maximum number of segments being tolled. In this case, the marginal effect of installing an additional gantry tends to decrease gradually with the number of gantries. Depending on the GDP growth, the marginal effect may be almost null or even negative for a large percentage of tolled segments, which suggests the implementation of a reasonable/optimal solution with some non-tolled segments.

In sum, the results from the model application demonstrate that different macroeconomic situations require different approaches. Particularly, the definition of toll prices per kilometre may induce significant variations in the revenue and traffic volume. In future research, additional variables characterizing the economic environment should be considered to test the sensitivity of the model. A more complex model of trip generation may replace the simplified drivers' choice model, allowing a more accurate analysis of the effects of different estimators and scenarios, but affecting the easiness of data collection and model application.

\section{References}

Al-Deek, H. M.; Radwan, A. E.; Mohammed, A. A.; Klodzinski, J. G. 1996. Evaluating the improvements in traffic operations at a real-life toll plaza with electronic toll collection, ITS Journal - Intelligent Transportation Systems Journal 3(3): 205-223. https://doi.org/10.1080/10248079608903720

Attard, M.; Ison, S. G. 2010. The implementation of road user charging and the lessons learnt: the case of Valletta, Malta, Journal of Transport Geography 18(1): 14-22. https://doi.org/10.1016/j.jtrangeo.2009.05.009
Banister, D. 2007. Sustainable transport: challenges and opportunities, Transportmetrica 3(2): 91-106. https://doi.org/10.1080/18128600708685668

Chen, C.-D.; Fan, Y.-W.; Farn, C.-K. 2007. Predicting electronic toll collection service adoption: An integration of the technology acceptance model and the theory of planned behavior, Transportation Research Part C: Emerging Technologies 15(5): 300-311. https://doi.org/10.1016/j.trc.2007.04.004

Danczyk, A.; Liu, H. X. 2011. A mixed-integer linear program for optimizing sensor locations along freeway corridors, Transportation Research Part B: Methodological 45(1): 208217. https://doi.org/10.1016/j.trb.2010.04.002

De Palma, A.; Proost, S.; Van der Loo, S. 2011. Network development under a strict self-financing constraint, Networks and Spatial Economics 12(1): 109-127. https://doi.org/10.1007/s11067-010-9152-5

Eliasson, J.; Hultkrantz, L.; Nerhagen, L.; Rosqvist, L. S. 2009. The Stockholm congestion - charging trial 2006: overview of effects, Transportation Research Part A: Policy and Practice 43(3): 240-250. https://doi.org/10.1016/j.tra.2008.09.007

Google LLC. 2017. Google Maps. Available from Internet: https://www.google.com/maps

Hau, T. D. 2005. Economic fundamentals of road pricing: a diagrammatic analysis, part I - fundamentals, Transportmetrica 1(2): 81-117. https://doi.org/10.1080/18128600508685644

Ieromonachou, P.; Potter, S.; Enoch, M. 2004. Adapting strategic niche management for evaluating radical transport policies - the case of the Durham road access charging scheme, International Journal of Transport Management 2(2): 75-87. https://doi.org/10.1016/j.ijtm.2004.09.002

IMT. 2017. Instituto da Mobilidade e dos Transportes. Available from Internet: http://www.imt-ip.pt (in Portuguese).

Jakobsson, C.; Fujii, S.; Gärling, T. 2000. Determinants of private car users' acceptance of road pricing, Transport Policy 7(2): 153-158. https://doi.org/10.1016/S0967-070X(00)00005-6

Levinson, D.; Chang, E. 2003. A model for optimizing electronic toll collection systems, Transportation Research Part A: Policy and Practice 37(4): 293-314.

https://doi.org/10.1016/S0965-8564(02)00017-4

Odeck, J.; Bråthen, S. 1997. On public attitudes toward implementation of toll roads - the case of Oslo toll ring, Transport Policy 4(2): 73-83.

https://doi.org/10.1016/S0967-070X(97)00008-5

Repolho, H. M.; Antunes, A. P.; Church, R. L. 2011. Optimization models for the location of motorway interchanges: concessionaires' perspective, Journal of Transportation Engineering 137(12): 962-970.

https://doi.org/10.1061/(ASCE)TE.1943-5436.0000293

Repolho, H. M.; Church, R. L.; Antunes, A. P. 2010. Optimum location of motorway interchanges: users' perspective, Journal of Transportation Engineering 136(11): 956-963. https://doi.org/10.1061/(ASCE)TE.1943-5436.0000162

Rotaris, L.; Danielis, R.; Marcucci, E.; Massiani, J. 2010. The urban road pricing scheme to curb pollution in Milan, Italy: description, impacts and preliminary cost-benefit analysis assessment, Transportation Research Part A: Policy and Practice 44(5): 359-375. https://doi.org/10.1016/j.tra.2010.03.008

Santos, G. 2005. Urban congestion charging: a comparison between London and Singapore, Transport Reviews 25(5): 511534. https://doi.org/10.1080/01441640500064439

Zarrillo, M. L.; Radwan, A. E.; Al-Deek, H. M. 1997. Modeling traffic operations at electronic toll collection and traffic management systems, Computers \& Industrial Engineering 33(3-4): 857-860. https://doi.org/10.1016/S0360-8352(97)00266-0 